\title{
Agricultural colleges and universities to build innovative talent training mode
}

\author{
Xiuying Li \\ Information technology teaching and Management Center \\ Jilin Agricultural University \\ Changchun,,China \\ 729738677@qq.com \\ $+8615543630576$
}

\author{
Dongju Du \\ College Animal Science and Technology \\ Jilin Agricultural University \\ Changchun,,China \\ lxy@jlau.edu.cn
}

\begin{abstract}
One of the core mission of universities is to cultivate innovative talents, and to achieve this goal, we must innovative training model . Innovative Talent Training Mode agricultural colleges and universities is a modern economy , a necessary requirement for agricultural development, the paper explore the meaning and significance of constructing personalized innovative talent training mode, discusses the agricultural colleges and universities to build innovative training model of the basic ways .
\end{abstract}

Keywords- personality ; innovation ; agricultural colleges and universities; personnel training mode

\section{INTRODUCTION}

With the demand for talent was gradual trend of diversity , agricultural colleges original traditional knowledge-based , application-oriented training model gradually exposed its drawbacks, on the one hand, personnel training mode too convergence, trained students in accordance with the unified standard mode are all the same product, the narrow range of knowledge, social adaptability and innovation capacity is not enough, can not meet the requirements of modern science and technology development and market economy. On the other hand, personnel training mode oversimplified, lack of flexibility, no longer suited to people-centered philosophy of education, can not meet the needs of students personality development , students do not meet the educational concept of lifelong learning . Therefore, we must be bold and innovative training model of the existing agricultural colleges and universities , build personalized innovative training model.

\section{CONNOTATION OF TRAINING ModE}

Training Mode is the guiding principle in certain theories of education and education , according to school personnel training objectives, organizational structure and operation mode style training objects taken a particular talent cultivation, strategies, systems and teaching activities in general. These organizations are formed and run style in practice a certain style and character, with a clear plan , systematic and normative. Professional setting mode, curriculum status, knowledge development, education planning mode , etc. are elements of the organizational form of teaching personnel training mode, they are training content management process to achieve training objectives and with directionality, and of each other there is an inherent logic of inter- relationships . Training model is subject to certain socio-political , economic and cultural constraints, different times, different social and political systems , personnel training mode is different ${ }^{[1]}$. Connotation training model has been determined, it limited the scope of its outreach, we can say that it is located in the school system for under, on top of teaching model of such a range of educational issues .

\section{INNOVATIVE TRAINING MODEL TO BUILD MEANING}

New Era is the core mission of higher education in cultivating innovative talents. To adapt to building an innovative country, the demand for knowledge-based economy and the development of mass higher education , colleges and universities must be creative and innovative training model to ensure the full implementation of quality education and improve the overall quality of college students, college students cultivate the spirit of innovation and innovation. And personnel training to achieve this goal , an innovative training model to build decisive . Training model of socio-economic factors, political, cultural , educational concepts such as subject to constraints . In building an innovative country 's macroeconomic background, the existing traditional knowledge-based, expertise -based training model gradually revealed its drawbacks. Therefore, based on the updated concepts of education, to build innovative undergraduate training mode select colleges and universities has become a reality ${ }^{[2]}$. Agricultural colleges and universities also have to take on building an innovative country , training to adapt to the development of modern agriculture, high-quality innovative talents historic mission , must be under the guidance of the scientific concept of development, updating educational concept, deepen the educational reform, to build higher agricultural hospital school innovative training model.

\section{BUILD PERSONALIZED INNOVATIVE TRAINING MODEL OF THE BASIC WAYS}

\section{A. changing concepts of education, adjusting traditional training objectives, establishing innovative personalized training objectives}

To meet the demand for talent diversification trend of social development, agriculture universities must actively change their thinking and education on the basis of the concept of education , training objectives for the school to re- locate, highlight the school professional characteristics to develop personalized innovative talents for the purpose of , adhere to the people-oriented concept of educating people , give full consideration to the student 's personality differences , interest differences, discrepancies in the ability 
to further enhance the dominant position of students for different levels of students to develop a training direction , focusing on students' awareness of innovation , creativity, innovation and innovative personality, to promote their creativity and personality development

\section{B. build a scientific and reasonable diversification and personalized training plan}

Credit is more in line with the rules of the market economy, reflecting the individual requirements of the students, help activate personnel training, therefore , agricultural colleges on the basis of training objectives repositioned on in accordance with the principles of knowledge , ability and quality of unity, steadily Credit reform, a comprehensive training program to optimize talent to build a scientific and rational diversification and personalized training plan to meet the different levels and types of student learning and training requirements

\section{Build adapt to modern agricultural development and innovation ability of teaching content}

Agricultural colleges and creative talents not only to meet the needs of regional agricultural economic development, but also to be familiar with and master the situation and development of world agriculture , therefore , in the formulation of school teaching programs must focus on cultivating high-quality personalized innovative personnel requirements, and vigorously reform the existing curriculum, update teaching content, build flexible , adapt to modern agricultural development and innovation ability of teaching content ${ }^{[3]}$.

Agricultural colleges curriculum system reform, and actively carry out the reform -oriented teaching and research in the 21st century content and curriculum system . Focus on building and improving the many courses and main courses with basic characteristics of modern agriculture, the establishment of dozens of core courses . Tracking Agricultural Development Trend Micro , will embody and reflect the interdisciplinary knowledge integration into new and interdisciplinary courses to promote an integrated curriculum structure.

According to the market demand and economic trends in agricultural science and technology development , to adjust disciplinary structure, the creation of new professional . To build on the existing curriculum updates out of the system , get rid of outdated textbooks and social development are not synchronized, select the characteristics of the times forefront of the development of new materials, effectively guide students to master the most cutting-edge scientific content, ensure that the advanced nature of the teaching content. And to develop goals based on talent, accelerate the construction of curriculum modules provide students with packaged selection mode, thus providing enough space for students to select and promote the formation and development of students' personality .

\section{According to the needs of innovative talents innovative practice teaching system}

Actively promote the reform of experimental teaching system, according to agricultural practice and strong features, experimental class hours is not less than one-quarter of the total credit hours. Reform of experimental teaching, will be scattered in various courses teaching content in accordance with the principles of academic disciplines, the formation of a comprehensive test program ${ }^{[4]}$. Integrate theory with practice, to form a complete practice teaching, quality education, innovative education system, and actively cooperate with enterprises, research units of production, and develop a good practice teaching base, take advantage of teaching, coordinating production practices combine to give students more practical training. Establish innovation credits.

\section{E. To innovative teaching methods}

Change the traditional teaching methods, highlighting the dominant position of students, fully care for and nurture students' curiosity, thirst for knowledge. Guide students to learn to think independently, to protect our students to explore the spirit and the desire to create , inspire students' creative thinking training, attention to student information collection and processing capabilities, the ability to acquire new knowledge, analyze problems and problem-solving skills development and training. Teaching methods and to constantly sum up experience, bold use of heuristics , seminar-style, type and case-based reviews and other teaching methods, the new teaching methods and has been teaching creative content organically integrate and mobilize the enthusiasm of students, reform existing and innovative teaching methods, due to the active use of new methods and new tools to bring information technology development .

\section{F. To reform personnel evaluation concept, building a new diverse talent evaluation system}

For a long time, China's higher education formed as examination scores as a standard mechanism for education and evaluation system can not meet the requirements of society and the fundamental laws of development of higher education . Personalized training of personnel determines the quality of talent development trend of diversification , diversification talent appraisal determines the diversification of education , agricultural colleges must establish a sound, scientific , pluralistic evaluation system , from focusing on the basics of assessment education evaluation system focusing ability to apply knowledge assessment up, the ability to use knowledge , research, innovation , analytical problem-solving skills as the main evaluation criteria , to enable students to take the initiative to establish the knowledge thinking , analytical applications , and innovation as fundamental teaching quality evaluation criteria, to stimulate students ' innovation courage and ability to think independently, to change a single closed book examinations , the use of flexible paper , broaden students' ideas on teaching management to correctly understand and deal with the uniform requirements and personality development relationship, attention to the relationship 
between principle and flexibility , consistency, unity and diversity , creating a relaxed environment for the growth of various educational objects ${ }^{[5]}$.

\section{CONCLUSION}

In short, to achieve the goal of innovative personnel training, must be innovative training mode, training mode according to the training objectives, training changed conditions change. This requires that the majority of agricultural colleges and educators to keep in practice for personnel training model development and innovation in order to achieve the goal to train innovative talents of modern social development needs .

\section{REFERENCES}

[1]Liu Guanglin. Agricultural Colleges and Universities to Build Innovative Undergraduate Training Mode [J]. Higher Agricultural Education, 2006, (4) :3-6.

[2] Wang Weilian. Training Model: the Most Important Issue of Education Quality [J] Chinese Higher Education, 2009 (8) :24-26.

[3] Zhou Quanxing. Training Model of Rational Thinking. [J]. Higher Education of Sciences. 2006 (1).

[4] Ma Dexiu. Looking for a Breakthrough Talent Training Mode is Committed to Developing Innovative Talents $[\mathrm{J}]$ Chinese Higher Education, 2006 (11): 20.

[5] Gu Mingyuan. Personalized Education and Training Model Innovation. [J]. Journal of the Chinese Society of Education, 2011 (10):5-8 